\title{
Maternal smoking is associated with impaired neonatal toll-like-receptor- mediated immune responses
}

\author{
P.S. Noakes, J. Hale, R. Thomas, C. Lane, S.G. Devadason and S.L. Prescott
}

ABSTRACT: Infants of smokers have much higher rates of respiratory infection, asthma and airway disease. The current study assessed the effects of maternal smoking in pregnancy on neonatal toll-like-receptor (TLR)-mediated immune responses as a possible contributing factor to the elevated rates of respiratory illness.

In a prospective birth cohort, the cord blood immune responses of neonates of smoking and nonsmoking mothers were compared. Maternal and cord serum cotinine were measured to confirm the level of cigarette smoke exposure. Neonatal cytokine responses were assessed to optimal doses of TLR2, TLR3, TLR4 and TLR9 ligands.

Cotinine levels confirmed maternal reporting of cigarette smoking in pregnancy, with significantly higher cotinine levels in maternal and cord blood compared with the nonsmoking group. Infants of smoking mothers showed significantly attenuated innate TLR-mediated responses compared with infants of nonsmokers.

The current findings indicate that in addition to effects on developing airways, maternal smoking also has significant immunological effects in pregnancy, which could contribute to the well recognised, subsequent increased risk of respiratory infections and asthma. These effects appear to be mediated through effects on toll-like receptor-mediated innate response pathways, which also promote regulatory pathways in the inhibition of allergic immune responses in the postnatal period, suggesting that other environmental interactions are highly relevant to the “hygiene hypothesis".

KEYWORDS: Cord blood, cotinine, cytokines, innate immunity, smoking, toll-like receptors

$\mathbf{T}$ he increased risk of infection in infants of smoking mothers is well recognized, as recently reviewed by DIFRANZA et al. [1], although the mechanisms have not been clearly established. In the relative absence of significant adaptive immune memory, newborn infants rely heavily on innate immune defence and maternal antibodies. The current study explores the novel hypothesis that maternal smoking causes a relative impairment of innate defences through effects on the developing immune system in pregnancy. It is speculated that these effects may not only contribute to the increased risk of infection, but may also be implicated in the increased rates of other forms of chronic inflammatory respiratory disease seen in these children [2] including asthma and allergic airway disease [3].

There is preliminary evidence that maternal smoking can influence foetal immune function

For editorial comments see page 675 . as measured by foetal Immunoglobulin (Ig)E production [4], and lymphoproliferative [5] and cytokine responses [6]. Preliminary studies by NOAKES et al. [6] also show that newborns of smoking mothers have altered cellular immune function. Other studies also suggest associations between maternal smoking and subsequent allergy [7, 8]. However, none of the previous studies has explored the potential mechanisms, or the possible effects, of maternal smoking on innate toll-like-receptor (TLR)-mediated microbial responses.

TLRs are essential to first line "innate" defence mechanisms that have evolved to recognise bacteria in the potential absence of established "memory". TLRs are found on many cells involved in immediate host defence including antigen presenting cells (APC) and CD4+/CD25+ Tregulatory cells [9], which also play a critical role in programming and regulating subsequent adaptive T-cell responses. Although these pathways

\section{AFFILIATIONS}

School of Paediatrics and Child Health Research, University of Western Australia, Perth, Australia.

\section{CORRESPONDENCE}

S.L. Prescott

School of Paediatrics and Child Health Research

University of Western Australia P0 Box D184

Princess Margaret Hospital

Perth WA 6001

Australia

Fax: 61893882097

E-mail: susanp@ichr.uwa.edu.au

Received:

April 112006

Accepted after revision:

July 052006

\section{SUPPORT STATEMENT}

S.L. Prescott was funded by the National Health and Medical Council of Australia 
are functional in neonates, they are generally less mature. With the rise in immune-mediated diseases, including asthma and allergic disease, it has been logically proposed that TLRmediated activation of both APC and regulatory T-cells may play an important role in reducing the risk of allergic responses in early life [10-12]. There is, therefore, a critical interest in early life factors that can influence maturation of TLR signalling and subsequent regulation of immune programming. The current study proposes that, in addition to the well documented effects on developing airways in utero, maternal smoking in pregnancy can also predispose to respiratory disease by effects on the developing immune system.

This prospective study investigated the effects of maternal smoking in pregnancy on these innate pathways, which do not require previous exposure or immunological memory, using specific microbial ligands for TLR2 (Pansorbin), TLR3 (polyinosinic:polycytidilic acid; poly I:C), TLR4/CD14 (lipopolysaccaride; LPS), and TLR9 (cytosine-phosphate-guanine; CPG, oligodeoxynucleotides; ODN). To the current authors' knowledge, this is the first prospective study to examine the effects of maternal smoking on these aspects of neonatal innate immune function. Maternal and foetal cotinine levels were measured to independently assess cigarette-smoke exposure, allowing examination of immune responses in relation to cotinine levels, as well as reported cigarette smoke exposure.

\section{METHODS}

\section{Study design}

The present prospective study investigated potential differences in innate immune development in infants whose mothers smoked in pregnancy with infants whose mothers have never smoked. Due to the nature of this exposure it was not possible to perform a randomised double-blind trial. However, for laboratory assessments, research personnel were unaware of smoking status and maternal allergy status. The study design also enabled the assessment of the effects of antenatal smoke exposure on neonatal immune function (cord blood immune responses). The study was approved by the Princess Margaret Hospital Ethics Committee, Perth, Australia.

\section{Study population}

Pregnant females, booked for antenatal appointments in local metropolitan hospitals (including St John of God Hospital, King Edward Memorial Hospital and Osborne Park Hospital), between August 2002 and October 2004 were screened by a researcher using a telephone or interview questionnaire. Healthy pregnant volunteers $(n=122)$ were recruited into the study. These included 60 smokers and 62 nonsmokers with approximately equal numbers of allergic $(n=62)$ and nonallergic $(n=60)$ participants in each group. Subjects were excluded from analysis if they delivered pre-term $(<36$ weeks gestation), or if there was any significant neonatal morbidity or disease. Maternal allergy status was assessed by skin prick test (SPT) to common allergens (house dust mite, grasses, moulds, cat, dog, feathers and cockroach). A wheal size of $\geqslant 3 \mathrm{~mm}$ above the negative control was considered positive. Females were defined as allergic if they have a history of disease and one or more positive SPT. Detailed information about antenatal health and smoking history was obtained using interview questionnaires and diary cards. All females recruited into the study received verbal and written information about the study and signed written consent.

\section{Cell preparation and culture}

Cord blood was collected into an equal volume of RPMI 1640 medium (Life Technologies, Mulgrave, Australia) containing preservative free heparin $\left(25 \mathrm{U} \cdot \mathrm{mL}^{-1}\right)$ as previously described [13]. Cord blood mononuclear cells (CBMC) were cryopreserved after collection for subsequent batch analysis. All samples were checked for viability on thawing. It has been previously shown that cryopreservation and thawing does not distort the pattern of mononuclear cell antigen-specific or polyclonal immune responses [14, 15]. The current authors have also since determined that cryopreservation does not significantly alter the pattern of TLR cellular function of cytokine profiles (Unpublished data; Prescott, SL; University of Western Australia, School of Paediatrics and Child Health).

In vitro CBMC response to TLR activation was assessed using similar cell culture systems as described previously [16, 17]. Optimal culture conditions for LPS [17] and CpG [16] have been previously determined by these authors, additional preliminary experiments were conducted (data not shown) to optimise responses to the other TLR ligands (Pansorbin and poly I:C) including the optimal cell numbers, ligand doses and the duration of incubation outlined below.

To determine TLR9 responses, CBMCs were cultured in duplicate $\left(5 \times 10^{5}\right.$ in $250 \mu \mathrm{L}$ AIM-V) in 96-well round-bottom plates either alone or together with optimal stimulating doses of CpG ODN (CpG B ODN, CpG C ODN, or non-CpG ODN control; all $1.66 \mu \mathrm{g} \cdot \mathrm{mL}^{-1}$; Coley Pharmaceutical Group, Ottowa, $\mathrm{ON}$, Canada). These plates were then placed in a $5 \% \mathrm{CO}_{2}$ incubator at $37^{\circ} \mathrm{C}$ for $48 \mathrm{~h}$.

To determine responses to TLR2, TLR3 and TLR4 activation, Pansorbin (0.1\%; Calbiochem ${ }^{\circledR}$, San Diego, CA, USA), poly I:C $\left(30 \mu \mathrm{g} \cdot \mathrm{mL}^{-1}\right.$; Sigma, Castle Hill, Australia) or LPS $\left(10 \mathrm{ng} \cdot \mathrm{mL}^{-1}\right)$, respectively, were added to $2.5 \times 10^{5} \mathrm{CBMC}$ in $250 \mu \mathrm{L} \mathrm{RPMI}$ (Gibco, Life Technology, Grand Island, NY, USA) plus 10\% foetal calf serum (not heat inactivated; Australian Biosearch, Perth, Australia) and incubated for $24 \mathrm{~h}$. For cultures with LPS, CBMC were primed with recombinant interferon (rIFN)- $\gamma$ $\left(10 \mathrm{ng} \cdot \mathrm{mL}^{-1}\right) 3 \mathrm{~h}$ prior to addition of LPS. After culture, the supernatants were collected and stored at $-20^{\circ} \mathrm{C}$ for cytokine analysis by ELISA or time resolved flurometry.

\section{Cytokine assays}

Cytokines in cell culture supernatants were quantified using a "sandwich-type" ELISA technique. Briefly, matched antibody pairs, consisting of unlabelled capture antibody and biotinylated detection antibody, and recombinant protein standards for IL-6, IL-10, tumour necrosis factor (TNF)- $\alpha$ and IFN- $\gamma$ were purchased from Pharmingen (Becton Dickinson, San Jose, CA, USA). Measurements for IL-12 p70 were made using matched antibody pairs and standards provided in commercial ELISA kits (Opt_EIA, Pharmingen) at the recommended concentration. A "responder" was defined as having cytokine responses at least two-fold over the limit of detection of the assay. The detection limits for the assays were $2.5 \mathrm{pg} \cdot \mathrm{mL}^{-1}$ for all cytokines. 


\section{Measurements of cigarette smoke exposure}

Cigarette smoke exposure was assessed by two methods: 1) maternal self-reporting as determined by the administration of a standardised questionnaires; and 2) cotinine analysis from cord and maternal blood (see below). Questionnaires were used to catergorise females (as determined by pack-yrs) as either smokers or nonsmokers. Pack-yrs equates to the average number of packs smoked per day multiplied by the number of years of cigarette use.

\section{Cotinine measurements}

Cord blood cotinine levels were measured using the liquid phase extraction methodology as described previously [18] with several modifications. Briefly, a total of $0.5 \mathrm{~mL}$ of cord blood serum (standard or test sample) and $40 \mu \mathrm{L}$ of internal standard (2-phenylimidazol, $25 \mu \mathrm{g} \cdot \mathrm{mL}^{-1}$ ) were added to $15 \mathrm{~mL}$ screw capped tubes. After addition of $1 \mathrm{~mL} 5 \mathrm{M}$ potassium hydroxide and $5 \mathrm{~mL}$ dichloromethane, tubes were shaken vigorously and then centrifuged at $3,220 \times g$ for $4 \mathrm{~min}$. The supernatants were discarded by aspiration. After evaporation to dryness under a gentle stream of nitrogen at ambient temperature, residues were reconstituted in $300 \mu \mathrm{L}$ of mobile phase. An aliquot $(25 \mu \mathrm{L})$ was injected into the high performance liquid chromatography (HPLC) system via the automatic sampler. The HPLC system consisted of a C18 reversed-phase cartridge column; an isocratic mobile phase, which was a mixture of aqueous phase, methanol and acetonitrile in the respective proportions $81: 10: 9(\mathrm{v} / \mathrm{v} / \mathrm{v})$ and a flow rate of $1.2 \mathrm{~mL} \cdot \mathrm{min}^{-1}$.

A solid phase extraction (SPE) procedure was performed for maternal cotinine determination as described previously [19] with the following adaptations; the SPE columns were preconditioned twice with $1 \mathrm{~mL} 100 \%$ methanol then twice with $1 \mathrm{~mL} 20 \mathrm{mM}$ sodium acetate buffer. Each sample (maternal serum) or standard $(2.0 \mathrm{~mL}$ in total) was loaded onto the SPE column and washed with $1 \mathrm{~mL}$ milli-Q water and $1 \mathrm{~mL} 10 \%$ aqueous methanol. Analytes were eluted twice with $0.5 \mathrm{~mL}$ elution buffer (95:5 methanol:ammonium hydroxide). Extracts were evaporated to dryness under a stream of nitrogen then reconstituted to $200 \mu \mathrm{L}$ with $20 \mathrm{mM}$ sodium acetate buffer. The supernatants were then transferred to autosampler vials and an aliquot $(25 \mu \mathrm{L})$ injected into the HPLC system. The HPLC system consisted of a $C^{18}$ reversed-phase cartridge column; an isocratic mobile phase, which was a mixture of milli-Q water, methanol, $20 \mathrm{mM}$ sodium acetate buffer $(\mathrm{pH}=6.8)$ and acetonitrile in the respective proportions 65:29:4:2 (v/v/v/v) and a flow rate of $1.2 \mathrm{~mL} \cdot \mathrm{min}^{-1}$.

\section{Statistical analysis}

Where possible, cytokine data underwent natural log transformation to obtain a log normal distribution and described by the geometric mean and 95\% confidence intervals. Relationships between categorical variables were analysed using Pearson's Chi-squared test. Comparisons between continuous variables were determined by independent, unpaired Students t-test (parametric data) or Mann-Whitney U-test for nonparametric data. Nonparametric correlations were determined by Kendall's tau-b to avoid "ties" in the data where a proportion of the variables of interest shared "zero" values. Multiple regression modelling was used to assess the effects of potential confounding factors. A p-value $<0.05$ was considered statistically significant for all analyses.

\section{RESULTS}

\section{Characteristics of maternal and neonatal populations}

Of the 155 females initially recruited into the study, 29 were excluded because of missed cord blood collections. The reasons for missed collections included: 1) transfer to a different hospital (not covered by ethics committee approval; $n=10) ; 2)$ obstetric emergencies $(n=6) ; 3)$ retained placenta $(n=5)$; or 4) placental tears during delivery $(n=8)$. The remaining 122 females included 60 smokers and 62 nonsmokers who were matched for maternal atopic status (table 1). There was no statistical difference in maternal age or parity between the females in the smoking group compared with the nonsmoking (control) group. There was no statistical difference in alcohol consumption before pregnancy or during any stages of gestation (not shown). Maternal smoking was associated with significantly lower levels of tertiary education $(p=0.002)$ and the use of illicit recreational drugs in pregnancy (including marijuana, ecstasy and amphetamines) was also significantly higher in this group $(\mathrm{p}<0.001)$. These group differences were included as potential confounding factors in all of the relationships examined below between maternal smoking and neonatal immune function.

Maternal smoking during pregnancy was also associated with a tendency for lower birthweight; however, this did not reach statistical significance $(p=0.312)$. There were no statistical differences in method of delivery, gestational age, birth length, head circumference, Apgar (appearance, pulse, grimace, activity, respiration) scores or infant sex between the two groups (table 1).

\section{Documentation of maternal smoking in pregnancy:}

Maternal cigarette smoke exposure was determined by two methods: 1) self-reporting as determined by the administration of a standardised health questionnaire; and 2) cotinine analysis from maternal blood.

As anticipated, there was a statistical difference between maternal serum cotinine levels $\left(\mathrm{ng} \cdot \mathrm{mL}^{-1}\right)$, pack-yrs and cigarettes smoked per day between the two groups (table 2). In addition, there was a significant positive correlation (Kendall's tau $\mathrm{b}=0.346 ; \mathrm{p}<0.001$ ) between maternal selfreported smoking (pack-yrs) during pregnancy and maternal serum cotinine levels (not shown).

\section{The effects of maternal smoking on TLR-mediated innate immune responses}

The current authors' observed that a number of aspects of cytokine responses were attenuated in newborns of smokers following TLR2, TLR3, TLR4 and TLR9 ligation, as outlined below.

\section{Effects on TLR2 signalling pathways}

Immune activation via TLR2 pathways (Pansorbin) was significantly attenuated in neonates born to smoking mothers compared with those born to nonsmokers. Specifically, the production of proinflammatory cytokines (IL-6 and TNF- $\alpha$ ) were attenuated in neonates of smoking mothers $(p=0.045$ and $p=0.004$ respectively; fig. $1 \mathrm{a}$ and $b$ ). Production of the key 


\begin{tabular}{|c|c|c|}
\hline $\begin{array}{ll}\text { TABLE } 1 & \text { Maternal and } \\
\text { study populat }\end{array}$ & hatal character & ics of the \\
\hline Characteristics & Smokers & Nonsmokers \\
\hline Subjects ${ }^{\#}$ & 60 & 62 \\
\hline \multicolumn{3}{|l|}{ Maternal characteristics } \\
\hline Age yrs & $29.62 \pm 0.71$ & $32.16 \pm 0.62$ \\
\hline Education greater year $10 / 11^{\#}$ & $40(70.2)$ & $53(93.0)^{*}$ \\
\hline $\begin{array}{l}\text { Recreational drug use during } \\
\text { pregnancy }\end{array}$ & $16(26.7)$ & $0(0.0)^{\star}$ \\
\hline \multicolumn{3}{|l|}{ Atopic status } \\
\hline SPT positive & $32(53.3)$ & $30(48.4)$ \\
\hline SPT negative & $28(46.7)$ & $32(51.6)$ \\
\hline \multicolumn{3}{|l|}{ Parity } \\
\hline 0 & 29 (48.3) & $21(33.9)$ \\
\hline 1 & $17(28.3)$ & $25(40.3)$ \\
\hline $2>$ & $14(23.3)$ & $16(25.8)$ \\
\hline \multicolumn{3}{|l|}{ Neonatal characteristics } \\
\hline \multicolumn{3}{|l|}{ Method of delivery of neonate } \\
\hline SVD & $45.0(75.0)$ & $44.0(71.0)$ \\
\hline Caesarian & $15.0(25.0)$ & $18.0(29.0)$ \\
\hline Gestational age days & $279.32 \pm 1.0$ & $277 \pm 1.0$ \\
\hline Birth weight $\mathbf{g}$ & $3387.58 \pm 57.19$ & $3467.90 \pm 54.63$ \\
\hline Birth length cm & $49.64 \pm 0.30$ & $49.58 \pm 0.25$ \\
\hline Head circumference $\mathrm{cm}$ & $34.57 \pm 0.18$ & $34.62 \pm 0.17$ \\
\hline Median 5 min AGPAR score & $9^{\circ}$ & $9^{+}$ \\
\hline \multicolumn{3}{|l|}{ Sex } \\
\hline Male & $24(40.0)$ & $26(41.9)$ \\
\hline Female & $36(60.0)$ & $36(58.1)$ \\
\hline
\end{tabular}

Data are presented as $n$, mean \pm SEM or $n(\%)$. SPT: skin prick test (wheal size $\geqslant 3 \mathrm{~mm}$ was considered positive); SVD: spontaneous vertex delivery; AGPAR: appearance, grimace, activity, respiration, determined by Mann-Whitney U-test; \#: $\mathrm{n}=57$ smokers and 57 nonsmokers; $": \mathrm{n}=57 ;^{+}: \mathrm{n}=62 ;{ }^{*}: \mathrm{p}<0.05$.

regulatory cytokine (IL-10) was also reduced in these newborns ( $p=0.014$; fig. 1c). There was a tendency for less frequent neonatal IL-10 responses to TLR2 activation (94.8\%) in the smoking group compared with the nonsmokers (100\%; $\mathrm{p}=0.077)$, however, this did not reach statistical significance (table 3). The production of other APC derived cytokines (namely IL-12) were not affected by maternal smoking (fig. 1d).
Effects on TLR3 and TLR4 signalling pathways

Newborns of smokers had attenuated inflammatory (TNF- $\alpha$ ) responses when stimulated by TLR4 ligand (LPS) and TLR3 ligand (poly I:C; $\mathrm{p}=0.044$ and $\mathrm{p}=0.034$, respectively), however there were no differences in IL-10 or IL- 6 cytokine responses with these microbial stimuli (table 4 ). There was no difference in IL-12 production via TLR3 or TLR4 ligation in the smoking group compared with the nonsmokers (not shown).

\section{Effects on TLR9 signalling pathways}

Maternal smoking was associated with attenuated IL-6 responses to TLR9 ligation (with $\mathrm{CpG}$ ODN), with significantly lower IL-6 responses to CpG C $(p=0.046)$, and a similar a trend for attenuated CpG B induced IL-6 levels ( $p=0.098$; fig. 2a). Unlike the other TLR responses, TLR9 induced T-helper (Th)1 $(\mathrm{IFN}-\gamma)$ responses tended to be stronger in newborns of smoking mothers. This effect was statistically significant for CpG B Th1 responses (IFN- $\gamma ; \mathrm{p}=0.032$; fig. $2 \mathrm{~b}$ ). There was also a trend for increased $\mathrm{CpG} \mathrm{C} \gamma$ responses, however this did not reach statistical significance, $(p=0.087)$. There was no relationship between maternal smoking and Th2 (IL-5 and IL-13) responses to $\mathrm{CpG}$ ODN (not shown).

All of the relationships mentioned previously were unchanged after accounting for any potential effects of between group differences in socioeconomic status and the use of other substances in pregnancy.

\section{Relationship between TLR responses and cotinine levels}

Cytokine responses were examined in relation to cotinine levels, which only reflect recent cigarette exposure (in the last 24-48 h). Consistent with the previous findings, there were consistent negative correlations between cotinine levels (in maternal and cord blood) and cytokine (IL-6, IL-10 and TNF- $\alpha$ ) responses to these TLR in the whole study population (table 5). These relationships were most apparent for IL-10 and TNF- $\alpha$ responses to TLR2 stimulation (Pansorbin) and TLR4 stimulation (LPS). This is likely to reflect the aforementioned effects of "smoking" per se on TLR function, because when nonsmokers were excluded from the analysis these relationships were no longer significant. In other words, variations in recent exposure (cotinine levels) did not predict variations in neonatal TLR function in "smoke-exposed" children. This could also indicate that the effects of maternal smoking in pregnancy on TLR function as shown previously, are more likely to be due to chronic exposure rather than exposure in the last $24 \mathrm{~h}$.

TABLE 2 Smoking characteristics of mothers in the study population in the smoking versus nonsmoking control group

\begin{tabular}{|c|c|c|c|}
\hline Characteristics & $\begin{array}{c}\text { Smokers } \\
\text { Current smokers }\end{array}$ & \multicolumn{2}{|c|}{ Nonsmokers } \\
\hline Pack yrs & $8.05(3.54-13.28)^{\star \star \star}$ & $0.00(0.00-2.67)$ & \\
\hline Cigarettes $\cdot$ day $^{-1}$ & $16.4 \pm 1.32^{\star \star \star}$ & $4.79 \pm 0.85$ & \\
\hline Years since quitting & & $5.03 \pm 0.71$ & \\
\hline
\end{tabular}



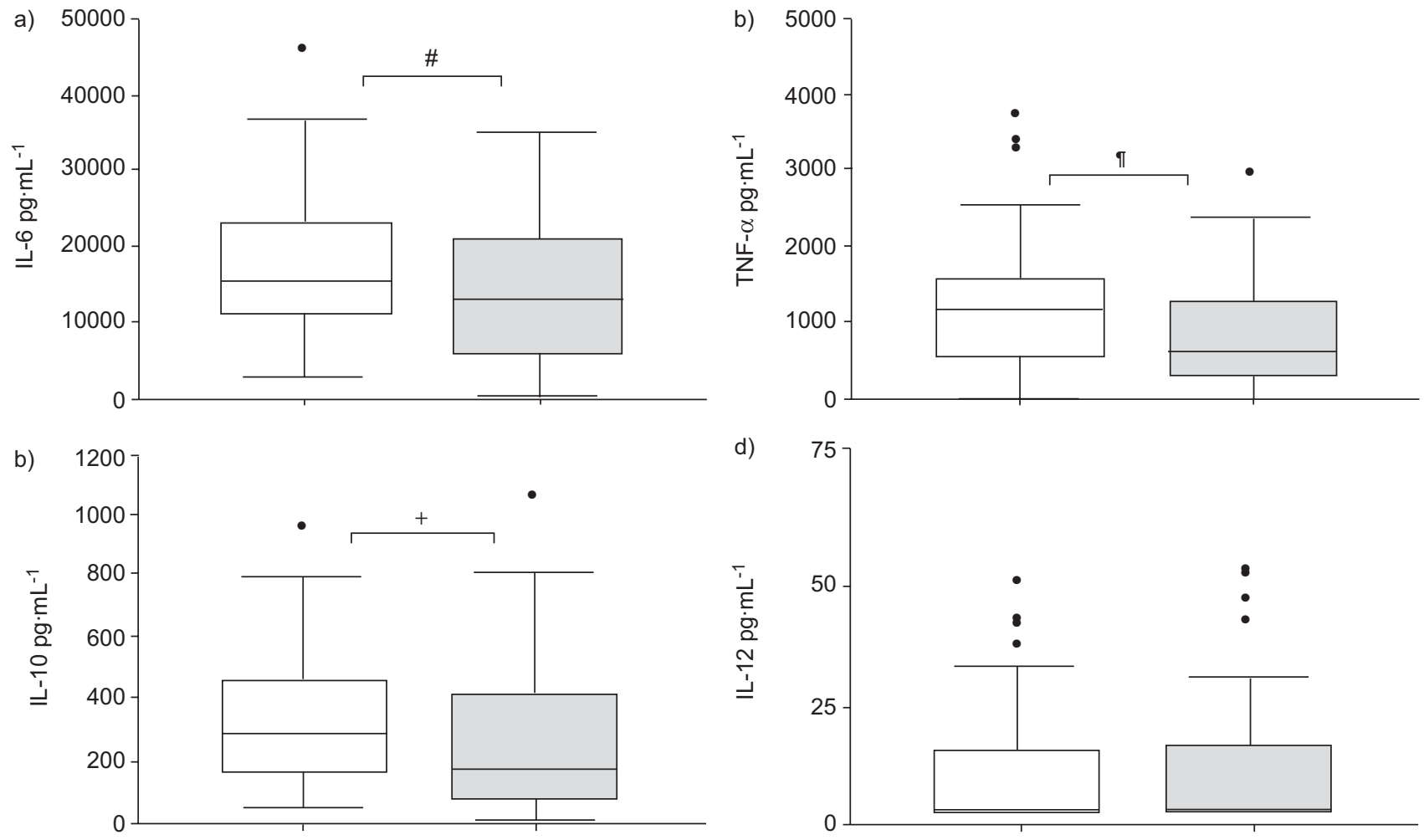

FIGURE 1. Comparison of neonatal cytokine responses to toll-like receptor-2 (Pansorbin) ligation between mothers who smoked during pregnancy ( $\square$ ) and those who did not ( $\square$ ). a) Interleukin (IL)-6, b) tumour necrosis factor (TNF)- $\alpha$, c) IL-10 and d) IL-12 responses are shown for Pansorbin. ${ }^{\#}: p=0.045 ;{ }^{\top}: p=0.004 ;^{+}: p=0.014$.

The effects of maternal allergy on TLR-mediated responses The current study was designed with equal numbers of allergic and nonallergic females in each group to minimise any confounding effects of allergic disease on the effects of smoking on immune function. The TLR-mediated responses in neonates of allergic and nonallergic females were also compared. In this study, maternal allergy did not have any significant independent effects on TLR responses. The only possible exception was that high-risk neonates (with maternal allergy) tended to have lower IL-10 responses to TLR2 (Pansorbin) stimulation, although this did not reach statistical significance ( $p=0.060$; not shown).

\section{Assessment of potential confounding effects:}

The factors that were examined as potential confounding influences were factors that: 1) could have potential effects on immune function, such as method of delivery, gestational age, and growth parameters; although these were not subsequently shown to differ between groups, and 2) other factors that were subsequently demonstrated to differ between the groups, such as educational level and use of other recreational drugs. Relevant factors were entered into multiple regression modelling to calculate adjusted weighted effects for maternal smoking and these variables. The relationships between maternal smoking status and immune function remained evident after these effects were accounted for.

AS seen in the present study, maternal smoking was associated with attenuated neonatal TLR-mediated responses to microbial agents. This included reduced production of both proinflammatory cytokines (IL- 6 and TNF- $\alpha$ ) and IL-10 regulatory cytokine compared with newborns of non-smoking mothers. The only exception to this was seen for Th1 IFN- $\gamma$ responses to TLR9 stimulation, which were significantly higher in those born to smokers.

\section{DISCUSSION}

The current study demonstrates for the first time that maternal smoking during pregnancy significantly inhibits neonatal innate immune responses to a variety of TLR ligands, with main effects on the production of APC derived cytokines. TNF$\alpha$ responses (primarily derived from monocytes) to TLR ligands (TLR2, 3 and 4) were attenuated in neonates exposed to tobacco smoking in utero, independent of other drug exposure. APC derived pro-inflammatory cytokine IL-6 production was also attenuated in these neonates following TLRmediated activation (via TLR2 and 9). Production of regulatory IL-10 responses was also significantly attenuated in response to TLR2 activation. Although IL-10 is produced by many cells, APC are a significant source in the context of microbial stimulation [20]. Despite these apparent effects on APC function the production of IL-12 was not significantly affected by smoking. This may be because IL-12 production is significantly attenuated in the neonatal period [21], whereas neonatal IL- 6 and IL-10 TLR induced responses are at adult levels, as recently shown PRESCOTT et al. [16]. Findings that smoking can interfere with APC responses to microbial agents, are supported by other studies that showed an in vitro immunosuppressive effect of nicotine on dendritic cell function, including antigen capturing, cytokine production (particularly IL-12 production), and eventually T-cell priming and 


\begin{tabular}{|c|c|c|c|c|}
\hline TABLE 3 & \multicolumn{4}{|c|}{$\begin{array}{l}\text { Cytokine responses of cord blood mononuclear } \\
\text { cells activated via toll-like receptor (TLR) ligation } \\
\text { expressed as a dichotomous value detected } \\
\text { versus non-detected }\end{array}$} \\
\hline \multirow[t]{2}{*}{ Cytokine } & \multirow{2}{*}{$\begin{array}{l}\text { Receptor } \\
\text { ligand }\end{array}$} & \multicolumn{2}{|c|}{ Responders } & \multirow[t]{2}{*}{ p-value } \\
\hline & & Smokers ${ }^{\#}$ & Nonsmokers & \\
\hline \multirow[t]{5}{*}{ IL-6 } & TLR2 (Pansorbin) & 96.6 & 100 & 0.150 \\
\hline & TLR3 (poly I:C) & 100 & 98.3 & 0.315 \\
\hline & TLR4 (LPS) & 100 & 100 & \\
\hline & TLR9 (CpG B) & 85.0 & 88.7 & 0.544 \\
\hline & TLR9 (CpG C) & 85.0 & 87.1 & 0.738 \\
\hline \multirow[t]{5}{*}{ IL-10 } & TLR2 (Pansorbin) & 94.8 & 100 & 0.077 \\
\hline & TLR3 (poly I:C) & 100 & 100 & \\
\hline & TLR4 (LPS) & 100 & 100 & \\
\hline & TLR9 (CpG B) & 100 & 100 & \\
\hline & TLR9 (CpG C) & 100 & 100 & \\
\hline \multirow[t]{5}{*}{ TNF- $\alpha$} & TLR2 (Pansorbin) & 98.3 & 100 & 0.311 \\
\hline & TLR3 (poly I:C) & 98.3 & 100 & 0.311 \\
\hline & TLR4 (LPS) & 100 & 100 & \\
\hline & TLR9 (CpG B) & 26.7 & 35.5 & 0.293 \\
\hline & TLR9 (CpG C) & 31.7 & 35.5 & 0.655 \\
\hline
\end{tabular}

Data are presented as \%. IL: Interleukin; TNF: tumour necrosis factor; poly I:C: polyinosinic:polycytidilic acid; LPS: lipopolysaccharide; CpG: cytosinephosphate-guanine. ${ }^{*}: n=60 ; ": n=62$.

polarisation [22]. It is not clear how long these effects on APC function might persist in the post-natal period. It is possible that these immune effects could contribute to the welldocumented increase in early post-natal susceptibility to respiratory tract infections in infants of smoking mothers [23].
Based on a number of recent findings, it is speculated that smoking may affect TLR signalling via nuclear effects on transcription factors. Production of inflammatory cytokines is under the regulation of control of several transcription factors, such as nuclear factor (NF)- $\mathrm{\kappa B}$ and activator protein (AP)-1 [24, 25]. In vitro studies have demonstrated that treatment with cigarette smoke extracts reduces pro-inflammatory, LPSinduced, TLR4 signalling by inhibiting transcription factor expression [26, 27]. More recently, VALACCHI et al. [28] demonstrated that acrolein (a major constituent of cigarette smoke) suppresses inflammatory processes in the airways by inhibiting epithelial chemokine IL-8 production, through a direct inhibitory effect on NF-kB activation. Thus, while there may be preliminary evidence that this occurs following direct mucosal exposure $[27,28]$, the present study provides evidence of additional systemic effects in utero.

It is difficult to determine if the observed effects on neonatal TLR function are the result of chronic or recent cigarette smoke exposure. However, the current findings suggest that these effects were due to chronic exposure, given that cotinine levels (which reflect exposure in the last 24-48 h) did not predict TLR function in the exposed group.

Innate responses (via TLR and other pathways) are an essential part of the first line of defence against invading pathogens. The resulting activation and maturation of APC and other cells of the innate immune system also provide essential signals for the initiation of more efficient cognate immune responses. Variation in the pattern and strength of TLR activation on APC can influence T-cell responses. For example, while low levels of bacterial LPS (TLR4 activation) favour Th2 differentiation [29], high doses favour Th1 differentiation [30, 31]. Thus, delayed maturation of APC function in the early postnatal period has been implicated as a major contributing factor in the development of Th2 allergic disease [17, 32]. The current

TABLE 4 Cytokine levels in supernatants of cord blood mononuclear cells stimulated with toll-like receptor (TLR) ligands ${ }^{\#}$ from neonates of mothers who smoked during pregnancy compared with nonsmoking mothers

\begin{tabular}{|c|c|c|c|c|c|c|}
\hline \multirow{2}{*}{$\begin{array}{l}\text { Cytokine } \\
\text { IL-6 }\end{array}$} & \multirow{2}{*}{$\begin{array}{l}\text { TLR Ligand } \\
\text { TLR2 (Pansorbin) }\end{array}$} & \multicolumn{2}{|c|}{ Smokers } & \multicolumn{2}{|c|}{ Nonsmokers $^{+}$} & \multirow{2}{*}{$\begin{array}{c}\mathbf{p} \text {-value } \\
0.045^{\star}\end{array}$} \\
\hline & & 12560 & $(5973-21139)$ & 15092 & (11302-23890) & \\
\hline & TLR4 (LPS) & 30106 & $(17559-36460)$ & 30000 & (24339-38826) & 0.293 \\
\hline & TLR9 $(\mathrm{CpG} \mathrm{B})^{\#}$ & 569.7 & (429.3-710.2) & 739.4 & (592.2-886.7) & 0.098 \\
\hline & TLR9 $\left(\mathrm{CpG}\right.$ C) ${ }^{\#}$ & 489.2 & $(370.1-608.2)$ & 703.1 & (530.9-875.3) & $0.046^{*}$ \\
\hline \multirow{3}{*}{ IL-10 } & TLR4 (LPS) & 304.2 & $(127.0-542.4)$ & 326.8 & (237.7-487.7) & 0.326 \\
\hline & TLR9 $(\mathrm{CpG} \mathrm{B})^{\S}$ & 205.9 & (182.1-229.5) & 223.1 & (193.3-252.8) & 0.367 \\
\hline & TLR9 $(\mathrm{CpG} C)^{\S}$ & 253.9 & (217.4-290.5) & 269.5 & (231.3-307.8) & 0.559 \\
\hline \multirow[t]{3}{*}{ TNF- $\alpha$} & TLR2 (Pansorbin) & 579.6 & (300.9-1293.2) & 1136.4 & $(579.4-1587.0)$ & $0.004^{*}$ \\
\hline & TLR3 (poly I:C) & 570.2 & $(231.0-1324.2)$ & 792.7 & $(495.8-1396.9)$ & $0.044^{*}$ \\
\hline & TLR4 (LPS) & 4094.40 & (1922.2-5690.0) & 4818.6 & (3619.5-6353.5) & $0.034^{*}$ \\
\hline
\end{tabular}

Data are presented as median (interquartile range), unless otherwise stated. IL: interleukin; TNF: tumour necrosis factor; poly I:C: polyinosinic:polycytidilic acid; LPS lipopolysaccharide; CpG: cytosine-phosphate-guanine. ${ }^{*}$ : pansorbin, poly I:C, LPS and CpG; ${ }^{\natural}: n=58 ;{ }^{+}: n=59 ;{ }^{\varsigma}:$ data was normally distributed. ${ }^{*}: p<0.05$. 

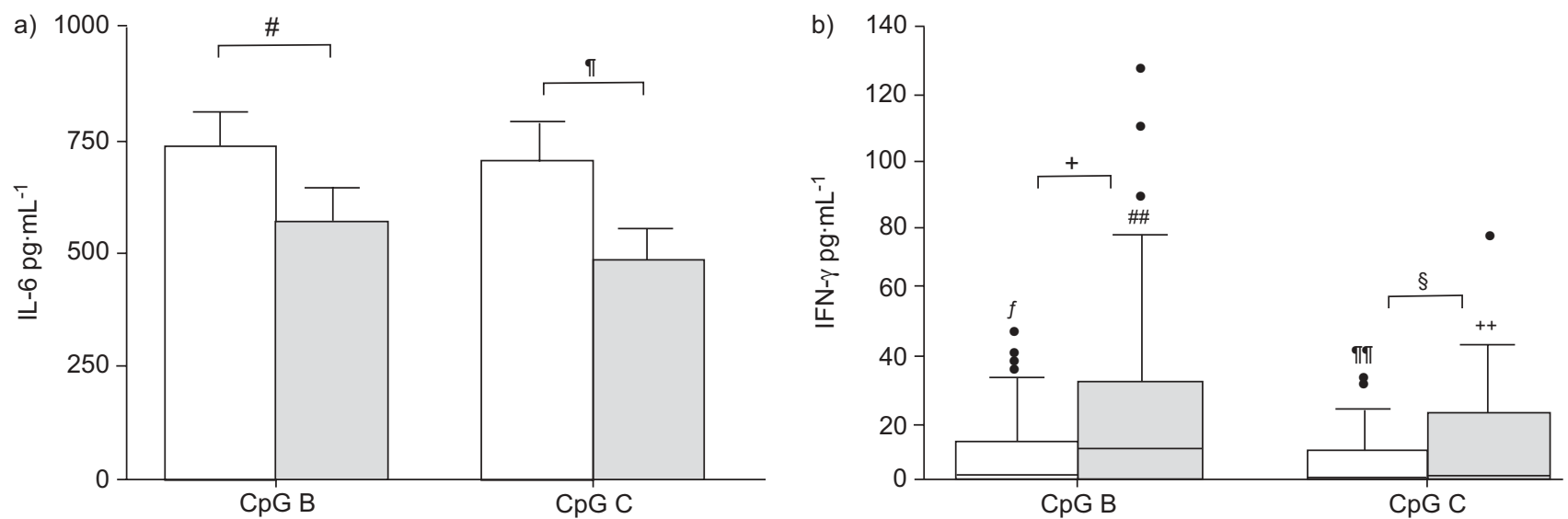

FIGURE 2. Comparison of a) neonatal interleukin (IL)- 6 and b) cord blood mononuclear cell interferon (IFN)- $\gamma$, responses to cytosine-phosphate-guanine (CpG) $B$ and $C$

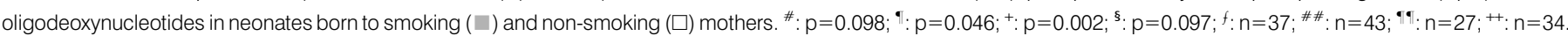

findings suggest that smoking may have direct effects on APC function in the antenatal period, as detected by impaired responses to microbial stimulation. This may have secondary effects in the post-natal period. On the one hand, any persistent immaturity of APC responses to bacteria could interfere with microbial-driven Th1 maturation. On the other hand, it could be argued that a resultant increased susceptibility to infection could provide a strong source of APC-driven Th1 immune maturation. However, there is still no definitive evidence in humans that infection or microbial exposure in early life protects from Th2-mediated allergic disease [33]. In animals, LPS exposure in pregnancy has been shown to prevent allergic

\begin{tabular}{|c|c|c|c|c|c|}
\hline TABLE 5 & \multicolumn{5}{|c|}{$\begin{array}{l}\text { Associations between maternal and cord blood } \\
\text { (CB) cotinine and neonatal interleukin (IL)- } 6 \text {, IL- } \\
10 \text { and tumour necrosis factor (TNF)- } \alpha \text { cytokine } \\
\text { responses to various toll-like receptor (TLR) } \\
\text { ligands }\end{array}$} \\
\hline \multirow[t]{2}{*}{ Cytokine } & \multirow{2}{*}{$\begin{array}{c}\text { Receptor } \\
\text { ligand }\end{array}$} & \multicolumn{2}{|c|}{ CB cotinine ${ }^{\#}$} & \multicolumn{2}{|c|}{ Maternal cotinine } \\
\hline & & Kendall $\tau \mathbf{b}$ & p-value & Kendall $\tau \mathbf{b}$ & p-value \\
\hline \multirow[t]{5}{*}{ IL-6 } & TLR2 (Pansorbin) & -0.114 & 0.119 & -0.131 & 0.051 \\
\hline & TLR3 (poly (l:C)) & -0.001 & 0.987 & -0.066 & 0.33 \\
\hline & TLR4 (LPS) & -0.065 & 0.375 & -0.078 & 0.249 \\
\hline & TLR9 (CpG B) & -0.123 & 0.093 & -0.096 & 0.152 \\
\hline & TLR9 (CpG C) & -0.022 & 0.769 & -0.037 & 0.579 \\
\hline \multirow[t]{5}{*}{ IL-10 } & TLR2 (Pansorbin) & -0.16 & $0.028^{*}$ & -0.168 & $0.012^{*}$ \\
\hline & TLR3 (poly (l:C)) & -0.057 & 0.433 & -0.103 & 0.125 \\
\hline & TLR4 (LPS) & -0.098 & 0.18 & -0.147 & $0.03^{*}$ \\
\hline & TLR9 (CpG B) & -0.136 & 0.063 & -0.107 & 0.107 \\
\hline & TLR9 (CpG C) & -0.117 & 0.112 & -0.061 & 0.359 \\
\hline \multirow[t]{5}{*}{ TNF- $\alpha$} & TLR2 (Pansorbin) & -0.164 & $0.025^{\star}$ & -0.138 & $0.04^{\star}$ \\
\hline & TLR3 (poly (l:C)) & -0.07 & 0.34 & -0.071 & 0.288 \\
\hline & TLR4 (LPS) & -0.144 & 0.051 & -0.138 & $0.041^{*}$ \\
\hline & TLR9 (CpG B) & -0.096 & 0.247 & -0.046 & 0.544 \\
\hline & TLR9 (CpG C) & -0.038 & 0.647 & -0.037 & 0.621 \\
\hline
\end{tabular}

Poly I:C: polyinosiic:polycydilic acid; LPS: lipopolysaccharide; CpG: cytosinephosphate-guanine. * : $n=108 ;$; $n=117$. *: $p<0.05$. sensitisation in rodents [34]. Associations between LPS exposure in pregnancy, cord blood IgE and subsequent disease risk suggests parallels in humans. The importance of "timing" is illustrated by animal studies, which show that LPS exposure before (but not after) allergic responses are established can prevent allergic sensitisation [35]. Thus, although effects of tobacco smoke may be more apparent in the post-natal period, the impact of earlier smoking-related immune effects may be critical.

In addition to effects on APC maturation, microbial activation is also important for activation of T-regulatory cells which also expresses TLR (TLR4, 5, 7 and 9) [9]. The current authors have not specifically addressed the effects of smoking on Tregulatory cells, but the observed effects on TLR4 and TLR9 function also have implications for T-regulatory cell activation, function and maturation. Dysfunction of these cells (allowing inappropriate allergen-specific responses) has also been implicated in the development of allergic disease. Although variations in microbial exposure have been clearly implicated in the allergy epidemic [12] other factors, such as genetic polymorphisms in TLR or environmental influences like smoking) could also alter patterns of APC and T-regulatory cell maturation, and contribute to the development of allergic disease. This needs to be explored in future studies.

In conclusion, the current findings show that maternal smoking has significant immunological effects in pregnancy that together with effects on developing airways, could contribute to the well-recognised subsequent increased risk of respiratory infections. These appear to be mediated through effects on toll-like-receptor-mediated innate response pathways that also promote regulatory pathways in the inhibition of allergic immune responses.

\section{ACKNOWLEDGEMENTS}

The authors would like to acknowledge the staff and patients who assisted in this study. We are particularly grateful to the obstetricians and midwives at King Edward Memorial Hospital and St John of God Hospital, Subiaco, Western Australia. Finally, the authors would like to acknowledge E. Pascoe for statistical advice. 


\section{REFERENCES}

1 DiFranza JR, Aligne CA, Weitzman M. Prenatal and postnatal environmental tobacco smoke exposure and children's health. Pediatrics 2004; 113: Suppl. 4, 1007-1015.

2 Chan-Yeung M, Dimich-Ward H. Respiratory health effects of exposure to environmental tobacco smoke. Respirology 2003; 8: 131-139.

3 Monteil MA, Joseph G, Chang Kit C, Wheeler G, Antoine RM. Smoking at home is strongly associated with symptoms of asthma and rhinitis in children of primary school age in Trinidad and Tobago. Rev Panam Salud Publica 2004; 16: 193-198.

4 Magnusson CG. Maternal smoking influences cord serum $\operatorname{IgE}$ and $\operatorname{IgD}$ levels and increases the risk for subsequent infant allergy. J Allergy Clin Immunol 1986; 78: 898-904.

5 Devereux G, Barker RN, Seaton A. Antenatal determinants of neonatal immune responses to allergens. Clin Exp Allergy 2002; 32: 43-50.

6 Noakes PS, Holt PG, Prescott SL. Maternal smoking in pregnancy alters neonatal cytokine responses. Allergy 2003; 58: 1053-1058.

7 Martinez FD, Antognoni G, Macri F, Bonci E, Midulla F, De Castro G, Ronchetti R. Parental smoking enhances bronchial responsiveness in nine-year-old children. Am Rev Respir Dis 1988; 138: 518-523.

8 Weiss ST, Tager IB, Munoz A, Speizer FE. The relationship of respiratory infections in early childhood to the occurrence of increased levels of bronchial responsiveness and atopy. Am Rev Respir Dis 1985; 131: 573-578.

9 Caramalho I, Lopes-Carvalho T, Ostler D, Zelenay S, Haury M, Demengeot J. Regulatory $\mathrm{T}$ cells selectively express toll-like receptors and are activated by lipopolysaccharide. J Exp Med 2003; 197: 403-411.

10 Holt PG, Macaubas C, Prescott SL, Sly PD. Microbial stimulation as an aetiologic factor in atopic disease. Allergy 1999; 54: Suppl. 49, 12-16.

11 Martinez FD, Holt PG. Role of microbial burden in aetiology of allergy and asthma. Lancet 1999; 354: Suppl. 2, SII12-SII15.

12 Wills-Karp M, Santeliz J, Karp CL. The germless theory of allergic disease: revisiting the hygiene hypothesis. Nat Rev Immunol 2001; 1: 69-75.

13 Prescott SL, Macaubas C, Holt BJ, Smallacombe et al, Transplacental priming of the human immune system to environmental allergens: universal skewing of initial $\mathrm{T}$ cell responses toward the Th2 cytokine profile. J Immunol 1998; 160: 4730-4737.

14 Macaubas C, Sly PD, Burton P, et al. Regulation of T-helper cell responses to inhalant allergen during early childhood. Clin Exp Allergy 1999; 29: 1223-1231.

15 Upham JW, Holt BJ, Baron-Hay MJ, et al. Inhalant allergenspecific T-cell reactivity is detectable in close to $100 \%$ of atopic and normal individuals: covert responses are unmasked by serum-free medium. Clin Exp Allergy 1995; 25: 634-642.

16 Prescott SL, Irwin S, Taylor A, et al. Cytosine-phosphateguanine motifs fail to promote T-helper type 1-polarized responses in human neonatal mononuclear cells. Clin Exp Allergy 2005; 35: 358-366.

17 Upham JW, Holt PG, Taylor A, Thornton CA, Prescott SL. HLA-DR expression on neonatal monocytes is associated with allergen-specific immune responses. J Allergy Clin Immunol 2004; 114: 1202-1208.

18 Ceppa F, El Jahiri Y, Mayaudon H, Dupuy O, Burnat P. High-performance liquid chromatographic determination of cotinine in urine in isocratic mode. J Chromatogr $B$ Biomed Appl 2000; 746: 115-122.

19 Kim I, Darwin WD, Huestis MA. Simultaneous determination of nicotine, cotinine, norcotinine, and trans- $3^{\prime}$ hydroxycotinine in human oral fluid using solid phase extraction and gas chromatography-mass spectrometry. $J$ Chromatogr B Analyt Technol Biomed Life Sci 2005; 814: 233-240.

20 Reis e Sousa C, Sher A, Kaye P. The role of dendritic cells in the induction and regulation of immunity to microbial infection. Curr Opin Immunol 1999; 11: 392-399.

21 Upham JW, Lee PT, Holt BJ, et al. Development of interleukin-12-producing capacity throughout childhood. Infect Immun 2002; 70: 6583-6858.

22 Nouri-Shirazi M, Guinet E. Evidence for the immunosuppressive role of nicotine on human dendritic cell functions. Immunology 2003; 109: 365-373.

23 Jedrychowski W, Flak E. Maternal smoking during pregnancy and postnatal exposure to environmental tobacco smoke as predisposition factors to acute respiratory infections. Environ Health Perspect 1997; 105: 302-306.

24 Nareika A, He L, Game BA, et al. Sodium lactate increases LPS-stimulated MMP and cytokine expression in U937 histiocytes by enhancing AP-1 and NF-kappaB transcriptional activities. Am J Physiol Endocrinol Metab 2005; 289: E534-E542.

25 Zhou L, Tan A, Iasvovskaia S, Li J, Lin A, Hershenson MB. Ras and mitogen-activated protein kinase kinase kinase-1 coregulate activator protein-1- and nuclear factor-kappaBmediated gene expression in airway epithelial cells. Am J Respir Cell Mol Biol 2003; 28: 762-769.

26 Kim E, Kang BY, Kim TS. Inhibition of interleukin-12 production in mouse macrophages by hydroquinone, a reactive metabolite of benzene, via suppression of nuclear factor-kappaB binding activity. Immunol Lett 2005; 99: 24-29.

27 Laan M, Bozinovski S, Anderson GP. Cigarette smoke inhibits lipopolysaccharide-induced production of inflammatory cytokines by suppressing the activation of activator protein-1 in bronchial epithelial cells. J Immunol 2004; 173: 4164-4170.

28 Valacchi G, Pagnin E, Phung A, et al. Inhibition of NFkappaB activation and IL-8 expression in human bronchial epithelial cells by acrolein. Antioxid Redox Signal 2005; 7: 25-31.

29 Eisenbarth SC, Piggott DA, Huleatt JW, Visintin I, Herrick CA, Bottomly K. Lipopolysaccharide-enhanced, toll-like receptor 4-dependent $\mathrm{T}$ helper cell type 2 responses to inhaled antigen. J Exp Med 2002; 196: 1645-1651.

30 Pasare C, Medzhitov R. Toll-like receptors: balancing host resistance with immune tolerance. Curr Opin Immunol 2003; 15: 677-682.

31 Pasare C, Medzhitov R. Toll pathway-dependent blockade of CD4+CD25+ T cell-mediated suppression by dendritic cells. Science 2003; 299: 1033-1036.

32 Prescott SL, Taylor A, King B, et al. Neonatal interleukin-12 capacity is associated with variations in allergen-specific 
immune responses in the neonatal and postnatal periods. Clin Exp Allergy 2003; 33: 566-572.

33 Nafstad P, Brunekreef B, Skrondal A, Nystad W. Early respiratory infections, asthma, and allergy: 10-year followup of the Oslo Birth Cohort. Pediatrics 2005; 116: e255-e262.

34 Blumer N, Herz U, Wegmann M, Renz H. Prenatal lipopolysaccharide-exposure prevents allergic sensitization and airway inflammation, but not airway responsiveness in a murine model of experimental asthma. Clin Exp Allergy 2005; 35: 397-402.

35 Tulic MK, Wale JL, Holt PG, Sly PD. Modification of the inflammatory response to allergen challenge after exposure to bacterial lipopolysaccharide. Am J Respir Cell Mol Biol 2000; 22: 604-612. 